\section{Delivering alcohol screening and alcohol brief interventions within general dental practice: rationale and overview of the evidence}

\author{
A. McAuley, ${ }_{1}^{1}$ C. A. Goodall, ${ }^{2}$ G. R. Ogden, ${ }_{1}^{3}$ S. Shepherd ${ }^{4}$ and K. Cruikshank ${ }^{5}$
}

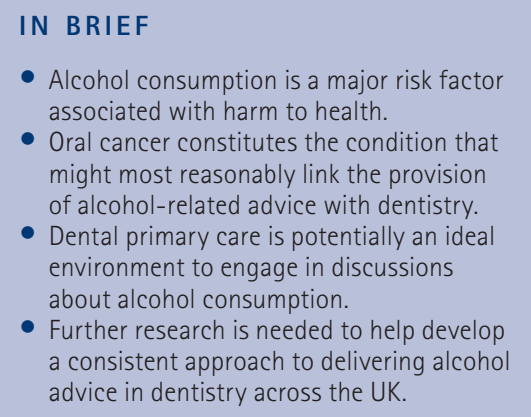

Alcohol consumption and affordability in the UK has increased over the last 50 years and is associated with a range of adverse oral health outcomes, the most serious of which, oral cancer, is also increasing in incidence. Despite this, routine screening and intervention relating to alcohol consumption within general dental practice remains uncommon. This review of the literature describes the background and outlines the evidence base for undertaking alcohol screening and delivering brief interventions in general dental practice. Consideration will be given to the rationale for, and range of issues related to, introducing this into general dental practice.

\section{INTRODUCTION}

Consumption of alcohol in the UK has almost doubled since 1950, with the rate of increase proliferating in the early 1990s. ${ }^{1}$ Alcohol is also now 70\% more affordable than it was in $1980 .{ }^{2}$ Parallel to this rise in consumption and affordability has been an increase in those drinking at harmful levels. There has been a similar concomitant increase in the mortality rates from liver cirrhosis such that Scotland now has one of the highest rates of liver cirrhosis mortality in Western Europe at a time when the rates in many other European countries are decreasing. ${ }^{3}$ Recent Scottish data suggest that 44\% of men and 34\% of women are drinking above the recommended daily guidelines (3-4 units for men, 2-3 units for women) on their heaviest drinking day in the

\footnotetext{
${ }^{*}$ Public Health Adviser, NHS Health Scotland, Public Health Science Directorate, Elphinstone House, 65 West Regent Street, Glasgow, G2 2AF; ${ }^{2}$ Clinical Lecturer in Oral Surgery and Honorary Specialist Registrar in Academic Oral \& Maxillofacial Surgery, Department of Oral Surgery, Glasgow University Dental School, 378 Sauchiehall Street, Glasgow, G2 3JZ; ${ }^{3}$ Professor of Oral Surgery, ${ }^{4} \mathrm{Clinical}$ Lecturer, University of Dundee Dental Hospital \& School, Park Place, Dundee, DD1 $4 \mathrm{HR} ;{ }^{5}$ Health Improvement Programme Officer, NHS Health Scotland, Thistle House, 91 Haymarket Terrace, Edinburgh, EH12 5HE

${ }^{*}$ Correspondence to: Mr Andrew McAuley Email: andrew.mcauley@nhs.net
}

\section{Online article number E15}

Refereed Paper - Accepted 7 December 2010

DOI: 10.1038/sj.bdj.2011.363

${ }^{\circledR}$ British Dental Journal 2011; 210: E15 past week ${ }^{4}$ and that one in 20 deaths is attributable to alcohol. ${ }^{5}$

Alcohol consumption, alongside smoking, increases the risk of developing oral cancer $^{6-8}$ and periodontal disease. ${ }^{9} 10$ Oral cancer is undoubtedly the most serious oral health disease associated with alcohol. The incidence of oral cancer in the UK is increasing, with oral cancer in males now more common than cervical cancer in females; indeed, no other cancer has shown such a significant increase in incidence. ${ }^{11}$ Despite improvements in the management and treatment outcomes for many other cancers, the long-term survival rates for oral cancer remain poor. While oral cancer is traditionally associated with older age groups, the recent increases in incidence are also significant across younger age groups and in both sexes. ${ }^{12}$ The incidence of oral cancer is also strongly related to social and economic deprivation, ${ }^{13}$ particularly for men, and this widening inequalities gap makes it all the more important that all avenues to address possible risk factors are explored. The recent increases in incidence have also been linked to the increases in alcohol consumption over the last 50 years, with one study confirming an increased likelihood of developing oral cancer for those drinking in excess of 20 units per week. ${ }^{6}$

Alcohol alone is associated with a range of other adverse oral health outcomes such as dental trauma, facial injury ${ }^{14}$ and non-carious tooth surface loss. ${ }^{15}$ Oral disease can also be a sign of poorer general health and wellbeing. In addition, excessive alcohol consumption causes a variety of medical problems, most notably liver disease, which can affect safe dental treatment and prescribing. Knowledge of a patient's alcohol status is therefore of direct relevance to the general dental practitioner (GDP). Despite this, routine screening and intervention relating to alcohol consumption within general dental practice is uncommon. ${ }^{16-20}$

\section{POLICY CONTEXT}

The British Dental Association Oral Health Inequalities Policy ${ }^{21}$ states that improving oral health should be part of the government's wider public health strategy across the UK, as many of the key factors for poor oral health are key risk factors for other conditions. One of these key factors is alcohol. The policy highlights that dentists and the dental team are ideally placed to provide preventive advice and health promotion messages to patients, as long as they are properly resourced to do so. Working collaboratively with other health and social care professionals on inequalities, dentists may go some way towards tackling not just oral health inequalities, but health inequalities in general.

The Department of Health formally recognised the widening of public health 
measures for dentists as a key strategic target in $2000 ;^{22}$ this included tobacco and alcohol misuse. In addition, the role of dental practitioners in identifying and addressing alcohol problems within their patient populations was proposed by the Scottish Executive in 2002. ${ }^{23}$ A national clinical guideline ${ }^{24}$ was then published (SIGN 74: The management of harmful drinking and alcohol dependence in primary care) which suggested that all healthcare professionals have a role to play in identifying harmful and hazardous drinkers. It also recommended the delivery of alcohol brief interventions (ABIs) for harmful and hazardous drinkers in primary care more generally. However, limited implementation of the national guideline ${ }^{25}$ and continuing increases in alcohol related harm in Scotland ${ }^{1}$ prompted the Scottish Government (SG) to create a set of targets for the delivery of ABIs $(149,449$ in the priority settings of primary care, emergency medicine and maternity services by 2011) supported by a substantial increase in funding for alcohol treatment and support services.

Using ABIs alone to reduce population alcohol consumption and health inequalities would have only limited effects. An effective national strategy that can facilitate such action needs to offer a multidimensional approach: building healthy public policy, creating supportive environments, strengthening community action, developing personal skills and reorienting health services, as outlined in the five principles of the Ottawa Charter for Health Promotion. ${ }^{26}$ Indeed, adoption of such an approach has proved hugely successful in tackling tobacco use in the UK. A similar national strategy to tackle excessive alcohol consumption is already being implemented in Scotland ${ }^{27}$ and has been proposed elsewhere in the UK. ${ }^{28}$

\section{SCREENING}

Evidence shows that the detection of alcohol-related problems and subsequent treatment is facilitated by use of appropriate screening tools. ${ }^{29}$ Despite this, few general dental practices in Scotland are systematically using a validated alcohol screening tool and there is no formally recognised screening tool specifically designed for use within general dental practice. The Alcohol Use Disorders
Identification Test (AUDIT), a ten-item screening tool with high reliability, sensitivity and specificity, ${ }^{30,31}$ has been validated as an accurate and reliable screening questionnaire for alcohol misuse detection in primary care. ${ }^{32}$ It has also been established that general dental practice is a similarly suitable primary care environment. ${ }^{33}$ Research in Scotland using the AUDIT screening tool reported $31 \%$ of dental patients drinking at hazardous, harmful or dependent levels, ${ }^{34,35}$ above the estimated 25\% expected to screen positive in the primary medical care environment. ${ }^{36}$ An abbreviated version of AUDIT, the three-item 'AUDIT-C', was used in an American study, which estimated that $25 \%$ of patients attending dental practice were drinking at hazardous levels. ${ }^{18}$

The Scottish Dental Clinical Effectiveness Programme (SDCEP) is developing guidance $^{37}$ that emphasises the need to collect better social history data (including alcohol consumption), which can help inform the dentist as to which information to give on health benefits, as well as highlighting risk factors for oral disease. As part of this guidance the SDCEP recommends, at a basic level, asking each patient about their alcohol consumption and mentions use of validated alcohol screening tools (SDCEP, emailed personal communication, 28 October 2010).

\section{ALCOHOL BRIEF INTERVENTIONS (ABIs)}

An alcohol brief intervention is a short, evidence-based, structured conversation about alcohol consumption that seeks in a non-confrontational way to motivate and support an individual to think about and/or plan changes in their drinking behaviour in order to reduce their consumption and/or their risk of harm. ${ }^{24} \mathrm{ABIs}$ offer more than simply giving advice. They typically use specific techniques for helping people to change their behaviour. Generally these involve motivational interviewing approaches and FRAMES (Feedback, Responsibility, Advice, Menu, Empathic, Self-efficacy) for the delivery of an effective alcohol brief intervention. ${ }^{24,29}$ ABIs can take as little as 5-10 minutes to deliver and there is no strong evidence to suggest that multiple sessions or even follow-up sessions to discuss alcohol consumption are more effective in reducing consumption than single sessions. ${ }^{32}$

A substantial body of research supports the conclusion that ABIs are effective in reducing alcohol consumption among hazardous and harmful drinkers. Indeed, a WHO review of 32 alcohol strategies and interventions found them to be among the most effective alcohol policies. ${ }^{38}$ The majority of this evidence base has been derived from studies conducted in the primary care setting within general medical practice and, to a lesser extent, Accident \&t Emergency settings. There is no evidence of ABIs' effectiveness in reducing alcohol consumption among those who are alcohol dependent ${ }^{24,29}$ and this would remain the reserve of specialist alcohol services.

Evidence supporting the effectiveness of ABIs in general dental practice is currently limited in comparison to other primary care medical services. ${ }^{39}$ However, recent research highlighting its potential in the primary care dental environment is beginning to emerge, ${ }^{17,19,34-36}$ with NICE public health guidance ${ }^{40}$ on preventing harmful drinking recommending dental surgeries as an appropriate setting for 'brief advice' about alcohol.

Moreover, there is significant plausible theory as to why ABIs should be delivered in this setting. With reference to ethical principles, ${ }^{41}$ ABIs can improve not only oral health, but also health more generally, they are equitable in that every dental patient who attends can be screened and offered an ABI, and they are sustainable because of their quick delivery and low implementation costs after initial training is completed. They also have the potential to impact on health inequalities, with recent figures showing that $65 \%$ of adults in Scotland are currently registered with a dentist, ${ }^{42}$ and other estimates showing that almost $80 \%$ of adults have had access to NHS general dental services over a sixyear period. ${ }^{43}$ Therefore ABIs delivered in dental practice can potentially impact not only on inequalities in oral health, but also more broadly on excessive alcohol consumption and the plethora of problems associated with it.

Currently, the involvement of GDPs in non-dental health promotion and preventative medicine is growing and there is willingness by dentists to increase their 
participation in this area ${ }^{20}$ and to develop appropriate counselling skills. ${ }^{44}$ Previous research ${ }^{45}$ reported a sizable majority $(86 \%)$ of Scottish dentists having already expanded their remit to include advice to patients on smoking cessation, with over half seeing a specific role for dentists in counselling patients to stop. Although there are some barriers to carrying out such interventions in general dental practice, dentists consider smoking cessation advice to be within their remit, as do the majority of their patients. ${ }^{45,46}$

The frequency and length of a typical dental appointment puts the dental team in a potentially ideal position to identify harmful/hazardous drinkers opportunistically and promote and/or deliver appropriate interventions. ${ }^{17}$ Dentists are familiar with early detection of oral cancer in practice, with visual screening of the oral mucosa (and onward referral) a routine procedure for the majority. ${ }^{47,48}$ A study in England also reported that dentists viewed that providing alcohol consumption advice would be of relevance to their practice. ${ }^{20}$

\section{BARRIERS}

Despite an acceptance by GDPs that provision of alcohol advice is beneficial, relevant and useful to their role, adoption into practice remains limited. ${ }^{17}$ In common with other healthcare professionals, ${ }^{49,50}$ some dentists have reported a reluctance and unwillingness to discuss alcohol consumption with their patients and provide advice on alcohol moderation, ${ }^{16,17,19,35,47,51}$ with GDPs less likely to provide advice than specialists. ${ }^{42}$

They report a range of barriers ${ }^{16-20,35,51}$ to routinely discussing alcohol with their patients. These range from lack of time to lack of funding and also a lack of sufficient training; these are not insignificant, as the way in which general dental practice is funded in Scotland does not emphasise preventive activities, which are not remunerated. They also highlight a lack of confidence, embarrassment and a fear of offending patients when discussing alcohol with their patients. Patients, however, have indicated that they are supportive of their dentist asking about their alcohol consumption and, where appropriate, advising them to cut down. . $^{19,34,35}$

Some of the issues identified as barriers for alcohol advice mirror those mentioned previously for tobacco smoking. This reluctance was in part overcome by a focus towards prevention of oral disease at both undergraduate and postgraduate level that is now more anchored in the dental curriculum than in previous years. Since the oral side effects of alcohol excess are largely linked with tobacco use, one way of overcoming a potential barrier towards alcohol advice is to link it with that of tobacco (where relevant).

Equipping young dentists properly with the skills to raise and deal with alcohol issues will address any role legitimacy and role adequacy issues they may have in relation to providing alcohol advice. Postgraduate education will also be needed to equip those dentists for whom this was not part of their undergraduate education and also to build on any existing training.

Funding issues may remain a problem, and in Scotland where dentists are paid on a fee-per-item scale we would recommend the addition of alcohol screening and ABIs to the fee scale. This may encourage some dentists to provide these services. However, financial incentives alone may not be sufficient to change professional practice. ${ }^{52}$ Time barriers are much more difficult to overcome; however, an investment of a few minutes in a one-off opportunistic intervention has huge cost/efficiency savings in the long term. It is also worth highlighting that the process of screening for alcohol misuse alone can have an effect and that this can take as little as 20 seconds. ${ }^{53,54}$ The value of screening as a brief intervention in its own right merits further exploration in terms of its applicability to general dental practice. The use of dental care professionals (DCPs) has also been suggested as a potential way to deliver health interventions in this setting and this may be more cost-effective than using dentists to provide this service. ${ }^{20}$

The potential of screening and ABIs within general dental practice opens up numerous avenues for future research. There is now very good evidence to support the efficacy of ABIs in various healthcare settings; however, there is a need to develop a screening and ABI specifically for use in general dental practice and to evaluate its feasibility, process and implementation as well as its effectiveness. In addition, elicitation studies have suggested that a key barrier to GDPs' involvement in the provision of ABIs is their perception that patients will not accept it as their role. ${ }^{19}$ Further clarification of Miller's work $^{18}$ on alcohol consumption levels of dental patients and barriers to implementation of screening and ABI among GDPs may allay many of those anxieties.

\section{CONCLUSIONS}

Alcohol is a key risk factor for oral cancer and is associated with poor oral health in general. General dental practices are attended by the majority of the adult population over time, therefore dental care settings offer significant potential as a setting where harmful and hazardous drinkers can be identified and offered an ABI.

The limited research to date has identified similar proportions of harmful and hazardous drinkers attending both general dental practice and general medical practice. There is a reported willingness from the dental workforce to become more involved in health promotion and prevention programmes, and similar support emerging from investigating patient views.

Barriers in relation to time, funding, training and attitude do exist and must be addressed before screening and intervention programmes for alcohol can be implemented. The success in using dental professionals to identify smokers and provide cessation advice/signposting is a positive example of how these barriers can be overcome and used to the advantage of public health. Therefore ABIs in general dental practice, delivered as part of a multi-dimensional approach to tackling excessive alcohol consumption, may offer significant potential to improve the oral and general health of the population.

1. Scottish Government. Changing Scotland's relationship with alcohol: a discussion paper on our strategic approach. Edinburgh: Scottish Government, 2008.

2. Information Services Division, NHS Scotland. Alcohol statistics Scotland 2009. Edinburgh: Information Services Division, NHS Scotland, 2009. http://www.alcoholinformation.isdscotland.org/ alcohol misuse/4951.html.

3. Leon $D \bar{A}$, McCambridge J. Liver cirrhosis mortality rates in Britain from 1950 to 2002: an analysis of routine data. Lancet 2006; 367: 52-56.

4. Corbett J, Dobbie F, Doig M et al. Scottish Health Survey 2009. Edinburgh: Scottish Government, 2010.

5. Grant I, Springbett A, Graham L. Alcohol attributable mortality and morbidity: alcohol population attributable fractions for Scotland. Edinburgh: Information Services Division, NHS Scotland, 2009.

6. Llewelyn J, Mitchell R. Smoking, alcohol and oral cancer in south east Scotland: a 10-year experience Br J Oral Maxillofac Surg 1994; 32: 146-152. 
7. McCoy G D, Wynder E L. Etiological and preventive implications in alcohol carcinogenesis. Cancer Res 1979: 39: 2844-2850.

8. Hashibe M, Brennan P, Benhamou S et al. Alcohol drinking in never users of tobacco, cigarette smoking in never drinkers, and the risk of head and neck cancer: pooled analysis in the International Head and Neck Cancer Epidemiology Consortium. J Natl Cancer Inst 2007; 99: 777-789.

9. Amaral Cda S, Luiz R R, Leão A T. The relationship between alcohol dependence and periodontal disease. J Periodonto/ 2008; 79: 993-998

10. Amaral Cda S, Vettore M V, Leão A. The relationship of alcohol dependence and alcohol consumption with periodontitis: a systematic review. J Dent 2009; 37: 643-651.

11. Speight P. Warnakulasuriya S, Ogden G. BDA advice sheet: oral cancer. British Dental Association: in press.

12. Conway D I, Stockton D L, Warnakulasuriya K A, Ogden G, Macpherson L M. Incidence of oral and oropharyngeal cancer in United Kingdom (1990-1999) - recent trends and regional variation. Oral Oncol 2006; 42: 586-592.

13. Conway D I, Petticrew M, Marlborough H, Berthiller J, Hashibe M, Macpherson L M. Socioeconomic inequalities and oral cancer risk: A systematic review and meta-analysis of case-control studies. Int J Cancer 2008: 122: 2811-2819.

14. Hutchison I L, Magennis P, Shepherd J P, Brown A E. The BAOMS United Kingdom survey of facial injuries part 1: aetiology and the association with alcohol consumption. British Association of Oral and Maxillofacial Surgeons. Br J Oral Maxillofac Surg 1998; 36: 3-13.

15. Robb N D, Smith B G. Prevalence of pathological tooth wear in patients with chronic alcoholism. Br Dent J 1990; 169: 367-369.

16. Macpherson L M, McCann M F, Gibson J, Binnie VI, Stephen $\mathrm{KW}$. The role of primary healthcare professionals in oral cancer prevention and detection. Br Dent J 2003; 195: 277-281.

17. Cruz G D, Ostroff J S, Kumar J V, Gajendra S. Preventing and detecting oral cancer. Oral health care providers' readiness to provide health behavior counseling and oral cancer examinations. J Am Dent Assoc 2005; 136: 594-601.

18. Miller P M, Ravenel M C, Shealy A E, Thomas S Alcohol screening in dental patients: the prevalence of hazardous drinking and patients' attitudes about screening and advice. J Am Dent Assoc 2006; 137: 1692-1698.

19. Shepherd S, Young L, Bonetti D, Clarkson J, Ogden G. Alcohol advice in primary dental care. J Dent Res 2009; 87: Abs 0186.

20. Dyer TA, Robinson P G. General health promotion in general dental practice - the involvement of the dental team. Part 2: A qualitative and quantitative investigation of the views of practice principals in South Yorkshire. Br Dent J 2006; 201: 45-51.

21. British Dental Association. The British Dental Association oral health inequalities policy. London: British Dental Association, 2009.

22. Department of Health. Modernising NHS dentistry implementing the NHS Plan. London: Department of Health, 2000
23. Scottish Executive. Alcohol problems support and treatment services framework. Edinburgh: Scottish Executive, 2002.

24. Scottish Intercollegiate Guidelines Network The management of harmful drinking and alcohol dependence in primary care: a national clinical guideline (updated). Edinburgh: Scottish Intercollegiate Guidelines Network, 2004

25. Rome A, Boyle K, Goodall J. Review of the implementation of the SIGN 74 Guideline of the management of harmful drinking and alcohol dependence in primary care and the Health Technology Assessment on the prevention of relapse in alcohol dependence. Edinburgh: NHS Health Scotland, 2008.

26. World Health Organisation. The Ottawa charter: principles for health promotion. Copenhagen: WHO Regional Office for Europe, 1986.

27. Scottish Government. Changing Scotland's relationship with alcohol: a framework for action. Edinburgh: Scottish Government, 2009.

28. House of Commons Health Committee. Alcohol: first report of session 2009-10. Volume 1. London: The Stationery Office, 2010.

29. Raistrick D, Heather N, Godfrey C. Review of the effectiveness of treatment for alcohol problems. London: National Treatment Agency for Substance Abuse, 2006.

30. Babor T, Higgins-Biddle J C, Saunders J B, Monteiro M G. The Alcohol Use Disorders Identification Test: guidelines for use in primary care (2nd ed). Geneva: World Health Organization, 1992.

31. Daeppen J B, Yersin B, Landry U, Pécoud A, Decrey H. Reliability and validity of the Alcohol Use Disorders Identification Test (AUDIT) imbedded within a general health risk screening questionnaire: results of a survey in 332 primary care patients. Alcohol Clin Exp Res 2000: 24: 659-665.

32. Kaner E F, Dickinson H O, Campbell F et al. Effectiveness of brief alcohol interventions in primary care populations. Cochrane Database Syst Rev 2007; 2: CD004148.

33. Harris C, Warnakulasuriya K A A S, Gelbier $S$, Johnson N W. Peters T J. Oral and dental health in alcohol misusing patients. Alcohol Clin Exp Res 1997; 21: 1707-1709.

34. Goodall C A, Crawford A, MacAskill S, Welbury R R. Assessment of hazardous drinking in general dental practice. J Dent Res 2006; 85: 1219.

35. Goodall C A, Welbury R R, Crawford A, MacAskill S. Do you take a drink? Asking patients about alcoho in general dental practice. Scottish Dentist 2007; March/April: 35-36.

36. Scottish Government. Guidance on HEAT targets issued to NHS Boards. Edinburgh: Scottish Government, 2007

37. Scottish Dental Clinical Effectiveness Programme. Guidance on comprehensive oral health assessment (draft). Dundee: Scottish Dental Clinical Effectiveness Programme, 2008

38. World Health Organization. Alcohol policy in the WHO European Region: current status and the way forward. Copenhagen: World Health Organization, 2005.
39. Dyer T A, Robinson P G. General health promotion in general dental practice - the involvement of the dental team. Part 1: a review of the evidence of effectiveness of brief public health interventions. Br Dent J 2006; 200: 679-685.

40. National Institute for Health and Clinical Excellence. Public health guidance 24. Alcohol-use disorders: preventing the development of hazardous and harmful drinking. London: National Institute for Health and Clinical Excellence, 2010.

41. Tannahill A. Beyond evidence - to ethics: decision-making framework for health promotion, public health and health improvement. Health Promot Int 2008: 23: 380-390

42. Information Services Division, NHS Scotland. Registrations with the NHS General Dental Service (GDS). http://www.isdscotland.org/isd/4680.htm.

43. Tilley C J, Chalkley M J. Measuring access to health services: General Dental Services in Scotland. Br Dent J 2005; 199: 599-601.

44. McCann M, Macpherson L M, Binnie V I, Stephen K W. A survey of Scottish primary care dental practitioners' oral cancer-related practices and training requirements. Community Dent Health 2000; 17: 24-30.

45. Chestnutt I G, Binnie V I. Smoking cessation counselling - a role for the dental profession? Br Dent $J$ 1995; 179: 411-415.

46. Campbell H S, Sletten M, Petty T. Patient perceptions of tobacco cessation services in dental offices. J Am Dent Assoc 1999; 130: 219-226.

47. Warnakulasuriya K A A S, Johnson N W. Dentists and oral cancer prevention in the UK: opinions, attitudes and practices to screening for mucosal lesions and to counselling patients on tobacco and alcohol use: baseline data from 1991. Oral Dis 1999 5: 10-14.

48. Kujan O, Duxbury A J, Glenny A M, Thakker N S, Sloan P. Opinions and attitudes of the UK's GDPs and specialists in oral surgery, oral medicine and surgical dentistry on oral cancer screening. Oral Dis 2005; 12: 194-199.

49. Aalto M, Pekuri P, Seppä K. Obstacles to carrying out brief intervention for heavy drinkers in primary health care: a focus group study. Drug Alcohol Rev 2003; 22: 169-173.

50. Nilsen P. Brief alcohol intervention - where to from here? Challenges remain for research and practice. Addiction 2010; 105: 954-959.

51. Shepherd S, Young L, Clarkson J E, Bonetti D, Ogden $G$ R. General dental practitioner views on providing alcohol related health advice: an exploratory study. Br Dent J 2010; 208: E13.

52. Town R, Kane R, Johnson P, Butler M. Economic incentives and physicians delivery of preventive care: a systematic review. Am J Prev Med 2005; 28: 234-240.

53. Jenkins R J, McAlaney J, McCambridge J. Change over time in alcohol consumption in control groups in brief intervention studies: systematic review and meta-regression study. Drug Alcohol Depend 2009; 100: $107-114$

54. McCambridge J, Day M. Randomized controlled trial of the effects of completing the Alcohol Use Disorders Identification Test questionnaire on self-reported hazardous drinking. Addiction 2008; 103: $241-248$ 